\title{
Toddler drowning in domestic swimming pools
}

\author{
C Blum, J Shield
}

\begin{abstract}
Aims-To identify how toddlers who drowned gained access to private swimming pools; to recommend preventive strategies to reduce the incidence of toddler drowning and near drowning.

Method-The study reviewed critically all completed investigations into the drowning deaths of toddlers aged 1-4 years reported to the state coroner $(n=33)$ as a result of unintentional submersion incidents in domestic swimming pools in Victoria, Australia, from 1 January 1992 to 31 December 1997.

Results-There was a predominance of 1 year olds, and boys. Forty six per cent of the children drowned in the three summer months. The majority of pools were in-ground; most were located on the child's home property. Over half the pools lacked fencing of any kind; of those that did have fences, only three appear to have met Australian standards.

Conclusions-More than half of the children studied drowned in unfenced pools and spas. In not one case did a child gain unaided access to a pool fitted with a fully functional gate and fence that met the Australian standard. Where children gained access to fenced pools, the majority did so via faulty or inadequate gates, or through gates that were propped open. This finding highlights the need for pool owners to install Australian standard approved fences and gates, and to maintain existing fences and gates regularly. Door locks and supervision were inadequate primary prevention strategies. (Injury Prevention 2000;6:288-290)
\end{abstract}

Keywords: toddler drowning; drowning; swimming pools; pool fencing

Drowning is the leading cause of unintentional injury death in toddlers aged 1-3 years in every state in Australia. ${ }^{1}$ In Victoria, an annual average of 10 children aged $0-14$ years drown in domestic swimming pools and spas. ${ }^{2}$ Australian and overseas studies have attempted to uncover effective preventive measures, with many recommending uniform pool fencing legislation as the principal preventive strategy. ${ }^{13-5}$ Four sided fencing, isolating the pool from other buildings or structures, is the preferred fencing type.

The Victorian State Government legislated fencing for all domestic swimming pools installed after April 1991. Further legislation in 1994 required the fencing of pools built before April 1991. Owners were given three years to comply with the retrospective legislation. ${ }^{2}$ Although fencing, or securing access from the house, is now mandatory for all pools in Victo- ria, little is known about how aggressively the laws have been enforced. Non-compliance attracts a maximum penalty of $\$ \mathrm{~A} 500,{ }^{6}$ yet anecdotal evidence suggests that few prosecutions have resulted. Four Australian standards are available to assist with compliance..$^{7-10}$

Pool fencing alone may not have reduced toddler drownings to the extent anticipated. ${ }^{11}$ In Queensland, after an initial large decline, toddler drownings have risen almost to prelegislation levels. Possible explanations are that the extensive media coverage of the issue before legislation being enacted has not been sustained, and compliance and enforcement are probably low. ${ }^{11}$

The aims of this critical review of a consecutive case series were to identify how toddlers who drowned gained access to private swimming pools, and to recommend preventive strategies to maximise the effectiveness of pool fencing in reducing the incidence of toddler drowning and near drowning.

\section{Method}

Case records of all completed investigations into deaths of children aged 1-4 years reported to the Victorian state coroner after drowning in domestic pools (including spas and wading pools), between 1992 and 1997, were examined to determine the mode of entry of each child. Thirty cases were obtained from the Victorian Institute of Forensic Medicine, two from the Consultative Council on Obstetric and Paediatric Mortality and Morbidity (A Altmann, personal communication, 1998), and one from the coroner's records. The few cases where the coroner's findings were pending were not available for analysis.

Details of age and gender, type and location of pool, fence characteristics, and the means by which the child gained access to the pool, were recorded onto a database. One case without full details was included in the analysis of age, sex and pool location, but excluded from all other analysis.

\section{Results}

The ages of the 21 boys and 12 girls (a ratio of 1.8:1) ranged from 1-4 years. Drownings decreased with increasing age. Forty six per cent of children drowned during the three months of the southern hemisphere summer (December to February).

Nineteen drownings occurred in in-ground pools, nine in above ground pools, and the remaining four in outdoor spas or wading pools. The pool was much more likely to be located on the child's home property than at a property the child was visiting. Only one child drowned in a neighbour's pool as a result of "trespassing". 
Key points

- Young children, particularly boys, are at great risk of drowning in swimming pools.

- Where pools were fenced, children gained access through faulty or inadequate gates, and gates that were propped open by adults.

- Door locks and supervision are inadequate primary prevention measures.

- Continuing media campaigns are needed to reinforce safe behaviours.

- Pool gates can be fitted with double locking devices.

- Pool owners can be encouraged to learn CPR.

- Governments can increase penalties for non-compliance with legislation.

- Coroners can develop standard reporting formats.

- Preventive efforts must be rigorously evaluated.

In 18 cases, the pool did not have complete fencing, including one instance where the fence was removed for renovation of the surrounding deck. Of the 14 pools with some form of fencing, only three appeared to have Standards Australia approved fencing, nine had nonstandard or faulty fences, and in two cases, fencing status was unclear.

In 11 of the 18 cases without fencing, the child was known to be outside the house immediately before the drowning incident, and seven children were thought to be inside. Of these seven children, five left the house through the back door which was reported to be "usually" locked, three of the doors were unlocked, one was left unlocked by the child's mother, and in one case the child had opened a faulty lock. One child left through a door known to be open and one climbed through a window.

Eight of the 14 children who gained access to fenced pools did so through inadequate or faulty gates. One climbed over or crawled under a non-standard fence, and three gained access after gates had been propped open. In two cases where fence compliance was not noted, the children were allowed into the pool area by parents.

Parents used several control measures to prevent their children gaining access to pools, including full or partial fencing, door locks, verbal warnings, and supervision.

Twenty eight children were in the care of one or both parents at the time of drowning. In 15 cases supervision was temporarily interrupted due to supervisors performing house or yardwork, answering the telephone, or participating in a social activity. In three cases there was confusion about who was supervising the child, in three cases the supervisor was watching television, and in 11 cases, supervision was interrupted in various ways.

\section{Discussion}

Only three of the 33 cases involved children gaining access to fully fenced pools. The over- whelming majority of pools were unfenced or inadequately fenced. Children who gained access to fencing that complied with the Australian standard were allowed into the pool area by parents or gained access through gates that were propped open.

\section{LIMITATIONS}

Cases where the coroner's findings were still pending were not available for inclusion. Most coronial reports did not specify whether or not isolation fencing was required at the time the drowning occurred; therefore, no inferences regarding legislative compliance can be made. Most research in the field comes from Australia, the United States, and the United Kingdom. Few countries other than Australia have much published experience with swimming pool fencing legislation, thus limiting international comparisons.

The most common age range for drowning in this series was 1-2 years. A New South Wales study also found this age group to be the most common. ${ }^{12}$ These two age groups are likely to be at greater risk due to high mobility and lack of understanding of dangers.

The predominance of males is consistent with the results of other studies, ${ }^{12-14}$ perhaps reflecting the natural differences in the developmental and exploratory characteristics of the genders. ${ }^{1}$

Although it is not surprising that more drownings occurred in summer, it was unexpected that so many drownings occurred outside the summer months. This could be due to relaxed vigilance outside the traditional swimming season. Similar results in a Brisbane study led the authors to speculate that "on a wintry day, however uninviting a cold pool may look in adult eyes, to a toddler an exposed water hazard may be fatally seductive". ${ }^{15}$

In common with other studies, ${ }^{5}{ }^{15}$ in-ground pools were most commonly implicated in toddler drownings, but little can be deduced from this finding without reliable data on the numbers of each pool type in the community. Anecdotal evidence suggests that in-ground pools are more numerous, and may also be more accessible to toddlers.

Toddlers drowning in their home pools is most likely due to increased exposure. However the 11 drownings that occurred on other properties support the enactment of uniform fencing regulations. In one study $21 \%$ of pool owners without fencing attributed this to lack of need as they had no children, yet nearly two thirds of these households had a young child visit within the previous six months. ${ }^{16}$ Altogether $57 \%$ of these owners also felt their property fencing was adequate to keep a child away from their pool. ${ }^{16}$ Notably, the one child in this study who drowned while "trespassing" managed to negotiate two property fences and a pool fence.

Two children were considered to be competent swimmers, one having attended 20 swimming lessons. Swimming lessons are not yet proven to be an effective preventive measure for children under 3 years of age. ${ }^{17}$ It is difficult to replicate the adverse conditions in which an 
immersion incident generally takes place, for example, an unexpected immersion while fully clothed. ${ }^{4}$ In one study, $10 \%$ of deceased children had been able to swim at least 10 metres. ${ }^{18}$ In such cases, parents may become complacent and relax their supervision.

Children gaining access through gates without locks, or with faulty locks, confirm other studies identifying the gate as the principal weakness in the pool fence. ${ }^{1216}$ The fences in the three drownings that occurred in pools that appeared to be fully compliant were rendered ineffective by the actions of adults in propping them open. A Brisbane study reported that 5\% of pool gates are propped open at any one time. ${ }^{19}$ Owners should also be aware of the importance of adequate maintenance of both gate and fence.

Door and window locks as the only physical barriers between child and hazard are unlikely to be effective in preventing toddler drownings, even when the locks themselves are child resistant. As door locks limit access to the outdoors, adults may leave them unlocked.

\section{Implications for prevention}

\section{EDUCATION}

Continuing media campaigns, reinforced by voluntary standards to ensure the media and advertising sectors depict fenced pools and spas, could assist in achieving greater compliance. Media campaigns can also encourage pool owners to adopt safety behaviours, such as maintaining fences, never propping gates open, removing obsolete pools, removing climbable objects from the pool surrounds, and learning cardiopulmonary resuscitation (CPR) skills. Parents and carers can be encouraged to adopt a policy of boycotting properties with unfenced pools, supervising children around pools irrespective of fencing status, learning CPR, and understanding that "floaties" are not substitutes for life vests.

Issues to be addressed through education include unrealistic expectations that young children can "swim", that they understand danger, and that they will obey instructions to keep away from the pool.

\section{ENGINEERING}

Pool gates could be designed with double locking devices and fitted with warning signs not to prop gates open. Some jurisdictions require CPR instructions and emergency response telephone numbers to be fitted to pool fences.

\section{ENFORCEMENT}

The state government could increase prosecutions and meaningful penalties for noncompliance. A requirement for CPR instructions, emergency response telephone numbers, and warning signs about propping gates open, to be fitted to every pool fence, could be added to the Australian standard. Local governments could register all pool owners, require annually updated CPR certificates, offer inspection and maintenance services, issue certificates of compliance, and monitor compliance (building surveyor, City of Moonee Valley, personal communication, 1998).

EVALUATION

The coroner could develop a standard reporting format for drowning fatalities to ensure uniform reporting, particularly details concerning the means of entry and compliance status. Investigation of every pool death should be mandatory.

A follow up study to track changes since the full implementation of mandatory fencing, particularly to monitor compliance, is needed to inform future preventive efforts. Meanwhile, it is crucial that media publicity is sustained until full compliance with legislation is achieved, and that education and media continue to reinforce the message of why fences are necessary.

The authors wish to acknowledge with grateful thanks the assistance and support of Dr Neale Jackson, RMIT University; Simon Jolly, Vicki Winship and David Freeman, Victorian Institute of Forensic Medicine \& State Coroner's Office; Dr Anne Altmann, Consultative Council on Obstetric and Paediatric Mortality and Morbidity; Fran McFadzen and Marilyn Lyford of the Australian Injury Prevention Network.

1 Cass DT, Ross FI, Lam LT. Childhood drowning in New South Wales 1990-1995: a population-based study. Med $\mathcal{F}$ Aust 1996;165:163-5.

2 Victorian Injury Surveillance System. Drownings and neardrownings at home. Hazard 1990;5:1-4.

3 Kemp A, Sibert JR. Drowning and near drowning in children in the United Kingdom: lessons for prevention. BMF 1992;304:1143-6.

4 Pitt WR, Balanda KP. Childhood drowning and near drowning in Brisbane: the contribution of domestic pools. Med $\mathcal{F}$ A ust 1991;154:661-5.

5 Wintemute GJ, Wright MA. The attitude-practice gap revisited: risk reduction beliefs and behaviors among owners of residential swimming pools. Pediatrics 1991;88:116871.

6 Building Control Commission. Silence: that's all you hear when a child drowns. Melbourne: Building Control Commission, 1997

7 Standards Australia. AS 1926.1-1993: Swimming pool safety, Part 1: fencing for swimming pools. Homebush: Standards Australia, 1993: 6-9.

8 Standards Australia. AS 1926.2-1995: Swimming pool safety, Part 2: location of fencing for private swimming pools. Homebush: Standards Australia, 1995.

9 Standards Australia. AS 2818-1993: Guide to swimming pool safety. Homebush: Standards Australia, 1993.

10 Standards Australia. AS 2820-1993: Gate units for private swimming pools. Homebush: Standards Australia, 1993: 7.

11 swimming pools. Homebush: Standards Australia, 1993: 7. swimming pools in Queensland since uniform fencing swimming pools in Queensland since unif

requirements. Med f Aust 1998;169:557-8.
Cass DT, Ross FI, Grattan-Smith TM. Child drownings: a changing pattern. Med f Aust 1991;154:163-5.

13 Brenner RA, Smith GS, Overpeck MD. Divergent trends in childhood drowning rates, 1971 through 1988. $\mathcal{F} A M A$ 1994;271:1606-8

14 Riley MD, Larson A, Langford J. Drowning fatalities of children in Tasmania: differences from national data. Aust N Z F Public Health 1996;20:547-9.

15 Pearn J, Nixon J. Swimming pool immersion accidents: an analysis from the Brisbane drowning study. Inj Prev 1997;3:307-9.

16 Balanda KP, Spinks D, Ring I, et al. The Brisbane home safety survey and its role in the Queensland pool safety campaign: domestic swimming pool fencing characteristics, compliance and attitudes. Health Promotion fournal of Australia 1991;1:37-42.

17 Asher KN, Rivara FP, Felix D, et al. Water safety training as a potential means of reducing risk of young children's a potential means of reducing ris
drowning. Inj Prev 1995;1:228-33.

18 Nixon J, Pearn J, Oldenburg B, et al. Review of countermeasures to reduce drowning, near-drowning and spinal injuries from diving into shallow water. Canberra: Commonwealth Department of Human Services and Health, 1995: 20. 19 Pitt R. Fences save lives. The Bulletin 1992; March 3: 57 